\title{
MANAJEMEN KEPEMIMPINAN SAYID IDRUS BIN SALIM ALJUFRI DALAM MENGEMBANGKAN LEMBAGA PENDIDIKAN ALKHAIRAAT
}

\author{
Ramlah Pontoh $^{1}$, Kasim Yahiji ${ }^{2}$, Lisdawati Muda ${ }^{3}$ \\ Pascasarjana IAIN Sultan Amai Gorontalo \\ Email:ramlahpontoh@gmail.com
}

\begin{abstract}
The leadership and managerial ability of the leader of an educational institution is one of the determinants of the development of the educational institution. This study aims to describe the portrait of educational management from Sayid Idrus bin Salim Aljufri in developing educational institutions. This study uses a qualitative approach. Data collection methods are observation, in-depth interviews and documentation. Data is analyzed by data reduction, presentation, and verification. The results showed that Sayid Idrus bin Salim Aljufri was a person who had a broad understanding of leadership and management, including management of education. This is indicated by its ability to develop educational institutions to carry out managerial functions of education management in planning, organizing, implementing and evaluating and monitoring. The application process by Sayid Idrus bin Salim Aljufri is a process of adaptation in accordance with the conditions and challenges of future education.
\end{abstract}

Keywords: Management, Leadership, Education.

\begin{abstract}
Abstrak
Kepemimpinan dan kemampuan manajerial pimpinan suatu lembaga pendidikan merupakan salah satu faktor penentu perkembangan lembaga pendidikan tersebut. Penelitian ini bertujuan untuk mendeskripsikan potret manajemen pendidikan dari Sayid Idrus bin Salim Aljufri dalam mengembangkan lembaga pendidikan. Penelitian ini menggunakan pendekatan kualitatif. Metode pengumpulan data adalah observasi, wawancara mendalam dan dokumentasi. Data dianalisis dengan reduksi data, presentasi, dan verifikasi. Hasil penelitian menunjukkan bahwa Sayid Idrus bin Salim Aljufri adalah orang yang memiliki pemahaman luas dalam kepemimpinan dan manajemen, termasuk manajemen pendidikan. Hal ini ditunjukkan oleh kemampuannya mengembangkan lembaga pendidikan untuk melaksanakan fungsi manajerial manajemen pendidikan dalam perencanaan, pengorganisasian, implementasi dan evaluasi serta pemantauan. Proses aplikasi oleh Sayid Idrus bin Salim Aljufri adalah proses adaptasi sesuai dengan kondisi dan tantangan pendidikan ke depan.
\end{abstract}

Kata Kunci: Manajemen, Kepemimpinan, Pendidikan 


\section{PENDAHULUAN}

Perkembangan pendidikan di Indonesia tidak dapat dipisahkan dari kontribusi para intelektual dan cendekiawan dalam merintis, membina dan mengembangkan lembaga pendidikan baik pendidikan umum maupun pendidikan Islam. Jauh sebelum kemerdekaan Indonesia,Ulama dan cendekiawan Muslim telah mendirikan berbagai lembaga pendidikan di Indonesia walaupun pengelolaannya masih sangat tradisional, seperti Pondok Pesantren Tebuireng yang didirikan oleh KH. Hasyim Asy'ari pada tahun 1899, Madrasah Adabiyah didirikan oleh Syekh Abdullah Ahmad pada tahun 1909 di Padang dan sebagainya. ${ }^{1}$

Banyak ulama dan cendekiawan Muslim membangun dan mengembangkan pendidikan di Indonesia timur. Salah satunya adalah Syech As'ad di Sengkang Selatan untuk mendirikan madrasah (sekolah agama dan umum) As'adiyah pada tahun 1931, di Palu, Sulawesi Tengah, Palu. Sayyid Idrus bin Salim Aljufrie juga mendirikan lembaga pendidikan Alkhairaat pada tahun 1930. Sayid Idrus bin Salim Aljufrie kemudian menjadi pemimpin besar di Palu Sulawesi Tengah dan seluruh wilayah di Indonesia bagian timur. Ia dikenal sebagai cendekiawan, pendidik, komunitas yang hebat dan juga guru tua. Ini berarti bahwa ia adalah guru pertama dan terpenting di Palu Sulawesi Tengah. Sayid Idrus bin Salim Aljufrie adalah pendiri dan pelopor utama lembaga pendidikan Alkhairaat di Indonesia dan telah berhasil mengembangkan pendidikan Alkhairaat mulai dari Sekolah Dasar hingga Pendidikan Tinggi (Universitas) hanya dalam dua dekade (1930-1956). ${ }^{2}$

\section{KEBERHASILAN SAYID UNTUK MENGEMBANGKAN}

Alkhairaat tidak terjadi secara alami tetapi didukung oleh konsep dan praktik manajemen kepemimpinannya yang efektif. Strategi dan praktik manajemen yang tepat dapat menunjukkan bentuk manajemen organisasi secara keseluruhan organisasi. Strategi dan manajemen Sayid Idrus yang efektif telah membawa Alkhairaat untuk mendapatkan dukungan dari semua masyarakat dan pemerintah daerah, baik di provinsi maupun di kabupaten dan pedesaan. Oleh karena itu, masalah utama dalam penelitian ini adalah bagaimana potret kepemimpinan dan manajemen pendidikan Sayid Idrus bin Salim Aljufrie untuk mengembangkan lembaga pendidikan Alkhairaat di Palu, Sulawesi Tengah, Indonesia.

\section{METODE PENELITIAN}

Penelitian ini difokuskan pada Gambar Manajemen Pendidikan Sayid Idrus bin Salim Aljufrie untuk mengembangkan pendidikan di Indonesia. Tokoh manajemen yang bersangkutan adalah bagaimana implementasi fungsi manajerial Sayid Idrus bin Salim Aljufrie untuk mengembangkan pendidikan Alkhairaat di Palu Sulawesi Tengah, Indonesia. Penelitian ini dilakukan di kota Palu di Sulawesi Tengah dan sekitarnya di pusat pendidikan Alkhairaat, menggunakan pendekatan kualitatif. Metode pengumpulan

h. 80

${ }^{1}$ M. Yunus. Sejarah Pendidikan Islam di Indonesia, (Jakarta : Hidakarya Agung, 1984),

${ }^{2}$ H.T. Yanggo,. Sayyid Idrus bin Salim Aljufri, Pendiri Alkhairaat dan Kontribusinya dalam Pembinaan Umat, (Jakarta : Gaung Persada, 2013), h. 70. 
data yang digunakan adalah observasi, wawancara mendalam dan dokumentasi. Teknik observasi digunakan untuk mengamati bukti perkembangan pendidikan Islam Alkhairaat di berbagai tempat dan wilayah. Wawancara digunakan untuk mengambil data sebanyak mungkin dari informan, yaitu murid-murid dekatnya masih hidup, tokoh agama dan masyarakat yang memiliki kedekatan dan pengetahuan Sayid Idrus bin Salim Aljufrie ketika memimpin pendidikan Alkhairaat (tahun 1930-1969). Wawancara dilakukan dengan "pengambilan sampel bola salju" ke sejumlah studi puisi dokumentasi Sayid Idrus bin Salim Aljufrie dalam bentuk manuskrip, kliping majalah dan surat kabar yang menulis tentang Sayid Idrus bin Salim Aljufrie dan pendidikan Alkhairaat sejak 1956 1998, serta dokumen-dokumen resmi Alkhairaat seperti Anggaran Dasar dan Anggaran Rumah Tangga dari Alkhairaat.

Uji validitas data dilakukan dengan triangulasi sumber dan metode. Data dianalisis dengan metode analisis deskriptif kualitatif . Teknik analisis data kualitatif dapat dilakukan dalam tiga siklus aktivitas dalam satu unit (interkoneksi). (1) Reduksi data adalah suatu bentuk analisis untuk mempertajam, mengklasifikasikan, mengarahkan, dan membuang data yang tidak perlu, untuk mengatur data yang akan dibuat dalam kesimpulan akhir dan verifikasi. (2) Penyajian data dilakukan melalui penyusunan informasi secara sistematis agar dipahami maknanya. Menurut Miles dan Huberman, tujuan penyajian data adalah untuk menemukan pola yang bermakna dan memberikan kemungkinan kesimpulan dan tindakan mereka. Penelitian ini menyajikan data dengan deskripsi naratif. (3) Kesimpulan adalah untuk menarik kesimpulan kemudian diverifikasi dengan meninjau catatan lapangan dan diskusi dengan kolega untuk mendapatkan kesepakatan antar-subyektif untuk mendapatkan kesimpulan yang tegas . ${ }^{3}$

\section{KONSEP DASAR DAN BATAS MANAJEMEN PENDIDIKAN}

Konsep dasar manajemen telah lama diterapkan dalam berbagai organisasi baik perusahaan, organisasi pemerintah maupun pendidikan. Manajemen organisasi membutuhkan kemandirian dan kerja sama sebagai strategi dalam kegiatan manajemen dan mengembangkan kerja sama untuk menciptakan inovasi yang efektif. Hal ini menunjukkan bahwa konsep dasar manajemen bersama digunakan manajemen pendidikan dasar dan organisasi pendidikan Islam, walaupun dalam praktiknya perlu penyesuaian sesuai dengan karakteristik organisasi.

Manajemen adalah kegiatan regulasi untuk mengelola dan memberdayakan semua potensi untuk mencapai tujuan organisasi secara efektif dan efisien melalui kegiatan perencanaan, pengorganisasian, penggerakan, dan pengendalian. Menurut George Terry, manajemen adalah proses khas perencanaan, pengorganisasian, dan pemantauan atau pengendalian untuk menentukan dan mencapai tujuan yang ditetapkan melalui pemanfaatan sumber daya manusia dan sumber daya lainnya. ${ }^{4}$ Manajemen juga berarti upaya untuk mencapai tujuan melalui kegiatan orang lain, sehingga manajer mengoordinasikan atau tindakan lain melalui perencanaan, pengorganisasian, penempatan, mobilisasi dan kontrol. Manajemen juga dapat diartikan sebagai kebutuhan

\footnotetext{
${ }^{33}$ Sugiyono, Metode Penelitian Kuantitatif, Kualitatif dan $R \& D$, (Bandung, Alfabeta , 2017) h. 246

${ }^{4}$ M. Yayat Herujito , Dasar-Dasar Manajemen, (Grasindo, Jakarta. 2001), h. 3.
} 
khusus semua lembaga dari yang terkecil hingga yang terbesar, karena setiap organisasi mengharuskan manajer untuk melakukan pekerjaan tertentu termasuk perencanaan, pengorganisasian, integrasi, pengukuran dan pengembangan yang lain .5

Manajemen bergerak dari proses perencanaan, pengorganisasian, mobilisasi dan pengawasan atau pengendalian dengan menentukan tujuan melalui pemanfaatan sumber daya manusia dan sumber daya lainnya. Manajemen sebagai proses tahapan yang harus dilakukan untuk mencapai tujuan yang ditetapkan. Demikian pula, dalam konteks manajemen pendidikan, fungsi manajemen perlu dilakukan seperti perencanaan, pengorganisasian, kepemimpinan dan pengawasan.

Batas manajemen pendidikan secara operasional diusulkan oleh Suryabrata sebagai berikut.

(1) Manajemen Pendidikan adalah suatu bentuk tenaga kependidikan yang kooperatif untuk mencapai tujuan pendidikan, (2) Manajemen Pendidikan adalah suatu proses pengorganisasian siklus pendidikan mulai dari perencanaan, diikuti dengan pengorganisasian, pengarahan, implementasi, pemantauan, dan penilaian upaya sekolah untuk mencapai tujuan, (3) Manajemen Pendidikan adalah upaya untuk membuat manajemen sistem pendidikan, (4) Manajemen Pendidikan adalah untuk memimpin kegiatan, pengambilan keputusan dan komunikasi dalam organisasi sekolah dalam upaya mencapai tujuan pendidikan. ${ }^{6}$

\section{SEKILAS TENTANG SAYID IDRUS BIN SALIM ALJUFRIE}

Sayid Idrus bin Salim Aljufrie lahir di Taris, sebuah kota yang terletak sekitar 5 km dari Kota Saiwon, ibukota provinsi Hadramaut di Negara Bagian Yaman Selatan, pada hari Senin Sha'ban ke-14 tahun 1309 H, sama dengan tahun 1889 M. Nama ayahnya adalah Sayid Salim bin Alwi Aljufri seorang ulama besar pada masanya yang berpengaruh dan dihormati oleh semua orang karena memiliki karisma yang tinggi. ${ }^{7}$

Sayid Idrus tumbuh dan berkembang di bawah perawatan langsung dari ayahnya di Hadramaut (Yanggo, 2013). Saat itu Hadramaut adalah salah satu daerah yang menjadi basis Islam di antara beberapa wilayah Muslim, dan menjadi sasaran penjajah Inggris. Ini membuat warga negara konsisten dengan nilai-nilai Islam karena para ulama merasa terus tertantang untuk mempertahankan keberlanjutan ajaran Islam dan kedaulatan negara. ${ }^{8}$ Dalam suasana seperti itu Sayid Idrus tumbuh sebagai anak muda yang konsisten dengan ajaran Islam dengan situasi di mana ia harus banyak belajar untuk melanjutkan perjuangan untuk Islam masa depan dan kedaulatan negara. Kondisi ini telah mempengaruhi sebagian besar hidupnya di masa depan. Kondisi ini telah menempa dirinya dan kepribadiannya, sehingga ia tumbuh sebagai salah satu karakter dalam Hadramaut untuk berperang melawan kolonial Inggris, baik untuk menegakkan Islam dan kedaulatan negara. Latar belakang ini menjadi salah satu alasan baginya untuk

\footnotetext{
${ }^{5}$ D.Julitriarsa dan J.Suprihanto.Manajemen Umum Sebuah Pengantar, ( Yogyakarta BPFE, 2012), h. 55.

${ }^{6}$ S.Suryabrata,. Proses Belajar Mengajar di Perguruan Tinggi, (Yogyakarta : Andi Offset, 2008), h.30.

${ }^{7}$ M.N. Sulaiman,. Biografi S. Idrus bin Salim Aldjufrie, (Palu : Press, 1988), h. 90.

${ }^{8}$ H.T. Yanggo,. Sayyid Idrus bin Salim Aljufri, Pendiri Alkhairaat dan Kontribusinya dalam Pembinaan Umat, (Jakarta : Gaung Persada.2013), h. 120.
} 
melanjutkan perjuangannya dalam pendidikan dan propaganda di Indonesia. Kegigihannya melawan kolonial Inggris, baik secara langsung maupun melalui perjuangan diplomatik, menjadikannya menjadi dirinya yang harus dibunuh oleh koloni Inggris. ${ }^{9}$

Sayid Idrus bin Salim Aljufrie kemudian memutuskan untuk meninggalkan Hadramaut dan pindah ke Indonesia. Baginya Indonesia adalah negara yang akan dapat mengembangkan perjuangannya untuk propaganda dan mengembangkan pendidikan. Silsilah neneknya berasal dari Bugis Sulawesi Selatan, Sengkang Wajo dan memiliki ikatan darah dengan keluarga kerajaan Matoa Riwajo. Oleh karena itu, dapat dikatakan bahwa meskipun Sayid Idrus lahir di Hadramaut Yaman tetapi ia juga merupakan keturunan bangsa Indonesia. Keputusannya untuk melanjutkan perjuangan dan pesannya kepada pendidikan Indonesia adalah keputusan strategis, karena ia juga seorang putra Indonesia. ${ }^{10}$

Silsilah ayah Sayid berasal dari Aljufrie. Dia adalah salah satu cabang keluarga Ba'Alawiy, keturunan cendekiawan besar dan masih memiliki garis keturunan dengan Ali bin Abi Talib, suami dari Fatimah putri nabi dan menjadi khalifah keempat Khulafaur Rasyidin, detail silsilahnya sebagai berikut : As-Sayyed Idrus bin Salim bin Alwi bin Saqqaf bin Muhammad bin Idrus bin Salim bin Husain bin Abdillah bin Syaikhan bin Alwi bin Abdullah At-Tarisi bin Alwi Al-Khawasah bin Abubakar Aljufri Al-Husain AlHadhramiy yang mempunyai jalur keturunan dari Sayyidina Husain bin Fatimah AzZahra Puteri Rasulullah SAW. ${ }^{11}$

Keturunannya dari beberapa pernikahan menggantikan dan melanjutkan perjuangan setelah Sayid Idrus meninggal. Putranya Sayid Muhammad bin Idrus Aljufrie menggantikannya dan meninggal pada tahun 1975. Dia digantikan oleh putranya Sayid Saqqaf bin Muhammad bin Idrus Aldjufrie (cucu pendiri Alkhairaat) sampai hari ini. Sayid Idrus adalah sosok yang hebat dan fenomenal di Indonesia timur tidak hanya karena ia adalah seorang sarjana yang hebat, tetapi keberhasilannya membangun dan mengembangkan pendidikan Alkhairaat untuk menyebar ke seluruh Indonesia, terutama Sulawesi, Kalimantan Timur, Maluku, dan Papua

\section{POTRET MANAJEMEN PENDIDIKAN SAYID IDRUS BIN SALIM ALJUFRI DALAM MENGEMBANGKAN PENDIDIKAN}

Keberhasilan Sayid Idrus untuk mengembangkan pendidikan di Indonesia telah dimulai dari perintis pertama pendidikan Alkhairaat 1930 hingga 1969 sebelum kematiannya. Itu tidak lepas dari kemampuan manajerialnya yang andal. Pola manajerial Sayid Idrus dalam merintis dan mengembangkan pendidikan Alkhairaat sangat penting untuk digunakan sebagai titik awal. Fenomena ini membuatnya menjadi agen sejarah dan bagian dari sejarah yang mengalami pertumbuhan dan dinamika. Ini terlihat jelas dalam

${ }^{9}$ Lihat, Lahuda dalam Yanggo,. Sayyid Idrus bin Salim Aljufri, Pendiri Alkhairaat dan Kontribusinya dalam Pembinaan Umat, (Jakarta : Gaung Persada, 2013), h. 97.

10 Ibid.

11 Idrus bin Salim Al-Jufri, https://id.wikipedia.org/wiki/Idrus_bin_Salim_Al-Jufri 
kebijakannya. Kepemimpinan Sayid Idrus adalah bentuk kepemimpinan transformasional

Langkah-langkah manajemen Sayid Idrus satu dijelaskan oleh siswa-siswanya Prof. Dr. H. M. Noor Sulaiman dalam sebuah wawancara:

Dalam membangun dan mengembangkan institusi pendidikan Alkhairaat, Sayid Idrus memulai dengan perencanaan yang hati-hati untuk mengoordinasikan semua elemen terkait seperti pemimpin agama dan masyarakat di Wani dan Palu. Dia mengumpulkan, memilih dan merekrut siswa (pengorganisasian), kemudian membuka madrasah pada waktu yang telah ditentukan sebelumnya. (Implementasi pendidikan). Ia juga selalu melakukan evaluasi dan pengawasan siswa yang telah dididik dalam pendidikan Alkhairaat secara berkala sebagai bentuk pertanggungjawaban hasil belajar yang diikuti. ${ }^{12}$

\section{Perencanaan Pendidikan}

Sejarah awal Sayid Idrus bin Salim Aljufrie adalah pembukaan institusi pendidikan di Palu, Sulawesi Tengah. Itu terinspirasi oleh undangan dan permintaan komunitas Islam dari Wani (sebuah kabupaten dengan sekitar $10 \mathrm{~km}$ utara Kota Palu). Melalui mediasi saudara mereka Sayyid Syech ibn Salim Aljufrie yang sebelumnya ke daerah itu, ia menjadi perantara kedatangan Sayid Idrus bin Salim Aljufrie di Palu . Menurut salah seorang siswa Sayid Idrus bin Salim Aljufrie, KH. Nawawian mengatakan bahwa: "Sikap sederhana (mutawadhi) dikembangkan oleh Sayid Idrus dan pengetahuannya yang rumit membuat orang tertarik dan memintanya untuk bisa menetap di Palu, Sulawesi Tengah, dan kemudian mendirikan lembaga pendidikan" .Sentimen mirip diungkapkan oleh Ma'ud Lahuda "Alkhairaat madrasah awalnya akan dibangun di Wani, tetapi karena tekanan dari masyarakat dan jamaah Arab di Palu yang tidak dapat dikembalikan lagi, akhirnya dia pindah ke Palu. "13

Setelah menyiapkan semua kebutuhan madrasah, tepat pada tanggal 11 Muharram 1349 H, sama dengan 30 Juni 1930 M, pendidikan Alkhairaat di Palu, Sulawesi Tengah, secara resmi dibuka. Sayid Idrus bin Salim Aljufrie telah merencanakan syarat dan kelengkapan sebagai institusi pendidikan / madrasah sebelum dibuka. Beberapa pernyataan di atas menunjukkan bahwa Sayid Idrus bin Salim Aljufrie memahami konsep sebenarnya dari rencana manajemen. Langkah-langkahnya untuk mendirikan lembaga pendidikan dimulai dengan menjalin komunikasi intensif dengan semua pihak, terutama orang-orang yang mendukung gagasan itu. Kemudian para siswa juga telah dipilih sebelum peresmian (peluncuran) lembaga pendidikan Alkhairaat.

Perencanaan pengembangan pendidikan lanjutan dilakukan oleh Sayid Idrus bin Salim Aljufrie dalam bentuk publikasi (promosi) madrasah kepada publik melalui kegiatan propaganda dengan memberikan dakwah serta memperkenalkan madrasah Alkhairaat. Prinsip dakwah adalah amar ma'ruf nahi al-munkar (mengundang kebaikan

\footnotetext{
${ }^{12}$ Yanggo, 2013. Sayyid Idrus bin Salim Aljufri, Pendiri Alkhairaat dan Kontribusinya dalam Pembinaan Umat.............. h. 46.

${ }^{13}$ Ibid.
} 
dan menghindari kejam), tanpa menyinggung kelompok tertentu, termasuk kelompok dari agama lain, adalah daya tarik utama bagi orang untuk menerima konsep dan ide-idenya.

2. Pengorganisasian Pendidikan

Sistem pengorganisasian pendidikan dilakukan oleh Sayid Idrus bin Salim Aljufrie melalui cara berikut.

a. Mengatur Penerimaan:

Sayid Idrus bin Salim Aljufri memiliki strategi untuk merekrut siswa lembaga pendidikan dengan mengorganisir potensi kelompok orang tertentu seperti; (1) masyarakat aristokrat (pemimpin masyarakat, pemimpin tradisional), (2) komunitas kaya dan (3) orang miskin. Siswa miskin mendapat perhatian khusus. Semua anak miskin dibebaskan dari uang sekolah dan biaya asrama .Strategi ini dimaksudkan untuk membuat institusi pendidikan Alkhairaat mudah dikenali oleh semua tingkatan dan strata masyarakat. Setiap lulusan dari institusi pendidikan Alkhairaat nantinya ditugaskan untuk mengasuh dan mengajar di sekolah di daerah masing-masing.

HM Noor Sulaiman mengatakan bahwa "Strategi organisasi untuk merekrut siswa juga dilakukan oleh Sayid Idrus melalui klasifikasi wilayah dan wilayah. Untuk area pasar yang kecil, Sayid Idrus merekrut dan membawa siswa baru sebagai perwakilan dari setiap daerah dan daerah yang ia kunjungi. Ini membuat lembaga pendidikan Alkhairaat dapat dengan cepat dikenal dan berkembang ke semua wilayah dan Sulawesi Tengah. Sayid Idrus berkoordinasi dengan para pemimpin agama dan pemimpin tradisional untuk mendapatkan siswa yang dapat mewakili daerah yang akan dididik di Alkhairaat. Idrus, Drs. KH. Sofyan Lahilote, MH, menjelaskan sebagai berikut:

Ketika Sayid Idrus bin Salim Aljufrie datang ke Manado, salah satu kerabat ayahnya melamar gurunya agar Sofyan Lahilote dapat diterima oleh Sayid Idrus untuk belajar di Palu. Sayid Idrus diam ... maka kerabat ayahnya diumumkan ... Sayid Idrus bahwa Sofyan adalah anak yang dapat mewakili Gorontalo, sehingga ada juga anak-anak yang belajar di Alkhairaat Palu. Oleh karena itu, Sayid Idrus menerima dan membawa Sofyan ke Palu untuk belajar di Alkhairaat. ${ }^{14}$

Strategi dan pendekatan untuk merekrut siswa dari banyak perwakilan daerah dan wilayah membuat pendidikan Alkhairaat dapat dengan cepat diakui dan menyebar ke berbagai tempat. Lebih mudah untuk mengoordinasikan bidang-bidang ini. Koordinasi dalam manajemen sangat penting, karena kegagalan program kemungkinan terjadi ketika tidak ada koordinasi atau koordinasi yang lemah. Koordinasi membuat sistem rekrutmen siswa lebih efektif dan efisien. Sistem ini juga menjadikan Sayid Idrus sebagai manajerial memahami kebutuhan komunitas pendidikan. Institusi pendidikan Alkhairaat secara konstan mendapatkan lebih banyak siswa dari tahun ke tahun. Sistem ini menciptakan perwakilan dari setiap daerah yang mengirim perwakilan mereka untuk belajar di lembaga pendidikan Alkhairaat setiap tahun. ${ }^{15}$

\footnotetext{
${ }^{14}$ Ibid, h. 110

${ }^{15}$ Ibid, h. 114.
} 


\section{b. Organisasi pembelajaran:}

H. M. Noor Sulaiman mengatakan bahwa "Sayid Idrus dalam mengelola lembaga pendidikan selalu mengatur siswa berdasarkan usia dan usia kelompok belajar. Demikian juga, perumusan materi pelajaran yang diajarkan diklasifikasikan dari usia anak". ${ }^{16}$ Misalnya, siswa di bawah 15 tahun tidak diizinkan membaca buku Ihya Ulumuddin oleh Imam Ghazali . Demikian pula, siswa di bawah 10 tahun tidak diajarkan pelajaran thahara, pernikahan dan masalah tasawuf. Ajaran Islam sebagai doktrin hukum yang sempurna dan ajaran menekankan perlunya menyampaikan materi Islam yang disesuaikan dengan usia siswa. Dr. KH. Abd. Bashir Mardjudo sebagai mahasiswa Sayid Idrus menjelaskan sebagai berikut:

Saya melihat Sayid Idrus langsung memperingatkan seorang guru KH Rustam Arsyad yang mengajarkan tasawuf di kelas I, yang menurut Sayid Idrus tasawuf itu tidak cocok untuk diajarkan kepada siswa di kelas I Aliyah (SMA) karena kemampuan dan jiwa siswa adalah belum siap ... ${ }^{17}$

Pertimbangan utama Sayid Idrus didasarkan pada pendekatan psikologi pendidikan dan perkembangan anak. Pada usia itu, anak-anak tidak memiliki daya tahan mental yang kuat untuk mencerna bahan penerapan hukum dan praktik batin, dan masih sulit untuk membedakan antara rasional dan emosional. Oleh karena itu, pemahaman tentang karakteristik siswa menjadi syarat penting untuk menyiapkan bahan ajar. ${ }^{18}$ Kemampuan Sayid Idrus untuk mengatur materi pembelajaran berdasarkan usia dan kemampuan siswa menunjukkan bahwa ia adalah seorang manajer pendidikan dan guru yang baik. Ia mampu memahami dengan benar teori dasar manajemen pendidikan dan pembelajaran. Manajer pembelajaran perlu memahami cara terbaik untuk menemukan kebutuhan siswa, baik secara individu maupun kolektif serta keragaman siswa sebagai tantangan yang dapat diatasi dengan sukses. ${ }^{19}$

Sayid Idrus juga dilakukan organisasi pendidikan dalam sistem pembelajaran. Ada dua pendekatan yang digunakan. Turath adalah pendekatan untuk belajar secara individu dengan memeriksa buku-buku kuning dan rohah adalah pendekatan untuk memeriksa buku-buku dan buku-buku tertentu dalam kelompok melingkar. Sistem Rohah juga diklasifikasikan menjadi dua kelompok, yaitu rohah guru dan rohah khusus untuk siswa. Menurut Raharjo, sistem rohah adalah sistem pembelajaran utama di lembaga pendidikan asrama. ${ }^{20}$

${ }^{16}$ Ibid.

${ }^{17}$ Ibid.

${ }^{18}$ Rusmawan, 2016, Faktor Yang mempengaruhi Kesulitan Belajar IPS Siswa Sekolah Dasar Jurnal-Cakrawala Pendidikan, Jurnal Ilmiah Pendidikan.

${ }^{19}$ S. Rudiyati, 2016. Peningkatan Kompetensi Guru Sekolah Inklusif dalam Penanganan Anak Berkebutuhan Khusus Melalui Pembelajaran Kolaboratif, Jurnal-Cakrawala Pendidikan, Jurnal Ilmiah Pendidikan.

${ }^{20}$ Fuaduddin, 2016. Pendidikan Ma'had Aly, Menyoal Tradisi Keilmuan Pesantren, Jurnal Edukasi; Jurnal Penelitian Pendidikan Agama dan Keagamaan. 
c. Organisasi Institusi:

Lembaga pendidikan Alkhairaat didirikan oleh Sayid Idrus bin Salim Aljufrie pada tahun 1930. Dekade kedua mengalami banyak perkembangan dan memiliki banyak cabang di berbagai daerah di Sulawesi Tengah dan Sulawesi Selatan. Secara umum, cabang di berbagai daerah terus dibuka. Itu membuatnya untuk membuat Dewan Regional (PD) dan Dewan Cabang (PC) di setiap wilayah dan wilayah, mulai dari tingkat provinsi hingga kabupaten. Konferensi pendidikan Alkhairaat pertama diadakan di Palu, Sulawesi Tengah pada 21 Januari hingga 25 Agustus 1956. Konferensi ini dihadiri oleh semua perwakilan Alkhairaat dari masing-masing wilayah dan wilayah. Kongres pertama menghasilkan komposisi kepengurusan sebagai berikut: Presiden PB Alkhairaat Center: Sayid Idrus bin Salim Aljufrie, Ketua: S. Abd. Rahman bin Syech Aljufri, Ketua Pertama: Ketua Mahfud Godal II: H.Rustam Arsyad, Sekretaris Jenderal / Sekretaris Jenderal: Z. Abidin Betalemba, Sekretaris I: M. Nawawian Abdullah, Sekretaris II: Sujudin L. Maradjati, Bendahara I: Mubarak Himran, Bendahara II: Alwi Intje Ote. Ini dilengkapi dengan 8 (delapan) komisioner (Dokumen V; AD / ART Alkhairaat, 1956). Selanjutnya, setiap lima tahun diadakan konferensi Alkhairaat sampai sekarang. ${ }^{21}$

Sayid Idrus membuat organisasi kelembagaan sistem pendidikan Alkhairaat berdasarkan kebutuhan layanan untuk pengembangan pendidikan Alkhairaat yang terus tumbuh dan berkembang di berbagai daerah dan wilayah. Ini juga berarti bahwa pendirian lembaga pendidikan milik semua orang, terutama komunitas Islam yang anak-anaknya berpartisipasi dalam pendidikan Alkhairaat. Kelanjutan institusi pendidikan Alkhairaat menjadi tanggung jawab semua pihak.

\section{d. Implementasi Pendidikan}

Implementasi awal sistem lembaga pendidikan di Indonesia saat itu, terutama yang ditandai dengan asrama, dikembangkan dari dua sistem pendidikan, yaitu sistem pendidikan tradisional (khalaqah) yang merupakan pendekatan pendidikan non-formal dan sistem pendidikan modern (klasikal). Menurut Rahardjo sistem Khalaqah adalah "suatu bentuk pengajaran dimana guru (kyai) dikelilingi oleh sejumlah siswa yang duduk bersila untuk mengajar buku / buku tertentu. Biasanya antara satu siswa dan lainnya membaca judul dan jenis buku yang berbeda". ${ }^{22}$

Sayid Idrus bin Salim Aljufrie menganggap bahwa sistem khalaqah adalah sistem yang efektif untuk digunakan sebagai model pembelajaran, karena sistem tersebut tidak memerlukan ruang kelas khusus untuk belajar. Dia juga dapat memberikan tempat belajar di mana ketika dia berada di rumahnya, di masjid atau tempat sholatnya, murid-muridnya dapat membawa buku itu dan membacanya di depannya.

Sistem khalaqah masih dianggap sebagai cara yang efektif dalam sistem pembelajaran pendidikan Islam. Sampai sekarang sistem ini masih dipertahankan, terutama untuk siswa dan siswa asrama di kompleks asrama Alkhairaat. Pada jam

${ }^{21}$ Yanggo,. Sayyid Idrus bin Salim Aljufri, Pendiri Alkhairaat dan Kontribusinya dalam Pembinaan Umat............... h. 78.

${ }^{22}$ D.Rahardjo, Bilik-Bilik Pesantren, (Jakarta : LP3ES. 2005), h. 93. 
sekolah, siswa masih belajar sesuai dengan kurikulum yang ditetapkan, kemudian setelah kembali ke asrama mereka diharuskan belajar dalam bentuk membaca buku atau buku untuk menentukan kyai. Hal ini dilaksanakan setelah maghrib sampai Isha berdoa, dan setelah subuh sholat sampai sebelum pergi ke sekolah.

Sistem klasikal sering juga disebut sebagai sistem pengajaran modern. Dalam sistem ini siswa belajar beberapa jenis pelajaran dalam hitungan jam yang telah ditentukan dan duduk mengenakan bangku, kursi dan meja. Setelah menyelesaikan materi pelajaran pada waktu yang ditentukan, siswa dapat memindahkan kelas ke tingkat yang lebih tinggi. Sistem ini diperkenalkan oleh kolonial. Indonesia awalnya menyebutnya sebagai sistem pendidikan colonial. ${ }^{23}$

Sayid Idrus bin Salim Aljufrie menggabungkan khalaqah dan sistem klasik. Selanjutnya, pada tahun 1950 sistem klasik dikembangkan oleh K. bin Sayid Salim Aljufri menjadi dua jenis pendidikan, yaitu sistem pendidikan untuk mempromosikan lebih banyak studi agama (sekolah Islam) dan sistem pendidikan yang lebih berorientasi pada mata pelajaran umum selain mata pelajaran agama (Umum Sekolah). Untuk lebih jelasnya sistem klasik yang dikembangkan oleh Sayid idrus bin Salim Aljufri dijelaskan secara rinci di bawah ini:

1) Sekolah agama (madrasah)

Jenis pendidikan ini memiliki tingkat dan orientasi pendidikan yang terdiri dari: Sekolah Dasar (MDA), Tingkat Sekolah Menengah (MTs), Sekolah Menengah Atas (MA), tingkat sekolah berasrama. Pendidikan asrama sepenuhnya dilakukan di Sekolah-sekolah Islam untuk menerima bimbingan langsung dari kyai.

2) Sekolah negeri:

Pendidikan Alkhairaat mengikuti sekolah-sekolah umum: Taman Kanak-kanak (TK), Sekolah Dasar (SD), Sekolah Menengah Pertama (SMP), Sekolah Menengah Atas (SMA / SMK), dan Universitas (PT). Sekolah negeri, selain mata pelajaran umum yang diajarkan, juga diberikan pengajaran agama untuk membuat lulusan tidak hanya bisa masuk universitas atau community college, tetapi juga bisa melanjutkan ke Perguruan Tinggi Islam seperti UIN / IAIN / STAIN dan sebagainya. Implementasi sistem pendidikan khalaqah telah diprakarsai oleh Sayid Idrus bin Salim Aljufrie yang dikombinasikan dengan sistem klasikal dan sampai sekarang masih dikelola oleh Badan Eksekutif Alkhairaat (PB).

3. Evaluasi dan Pengawasan Pendidikan

Pengawasan atau evaluasi bertujuan agar proses implementasi dapat dilakukan sesuai dengan rencana dan mengambil tindakan korektif untuk penyimpangan . Pengawasan dalam pendidikan adalah untuk mengetahui apa yang terjadi di lapangan, memeriksa perilaku tenaga kependidikan dalam menjalankan tugasnya, termasuk pencapaian pendidikan, metode kerja yang digunakan, cara mengelola uang, ketepatan waktu, semangat kerja dan sebagainya. ${ }^{24}$

Evaluasi dan supervisi pendidikan dilakukan oleh Sayid Idrus bin Salim Aljufrie sebagaimana dinyatakan salah seorang muridnya bernama Prof. Dr. H. M. Noor Sulaiman

\footnotetext{
${ }^{23}$ K.A. Steenbrink,. Pesantren, Madrasah, Sekolah, (Jakarta : LP3ES. 2013), h. 134.

${ }^{24}$ M. Pidarta, Manajemen Pendidikan Indonesia, (Jakarta : Bina Aksara. 2008), h. 55.
} 
sebagai berikut: "Saya telah melihat bahwa sistem evaluasi dilakukan oleh Sayid Idrus bin Salim Aljufrie dalam tiga bentuk berikut: (1) evaluasi implementasi pendidikan, (2) evaluasi kinerja guru dan (3) evaluasi hasil belajar siswa" Evaluasi pelaksanaan pendidikan dilakukan oleh Sayid Idrus bin Salim Aljufrie melalui atau mengunjungi cabang-cabang Alkhairaat di daerah, yang disebut safari wagon, karena ia pergi ke Alkhairaat di daerah selalu menggunakan kendaraan wagon. Gerobak (gerobak) adalah gerobak barang tradisional yang terbuat dari kayu dan ditarik oleh dua ekor sapi yang biasa digunakan oleh masyarakat pedesaan di wilayah Palu dan Sulawesi tengah. ${ }^{25}$

Salah satu muridnya bernama Drs. KH. Dahlan Tangkaderi mengatakan bahwa "dalam evaluasi dan pengawasan ini, ia menanyakan berbagai hal tentang pelaksanaan pendidikan dan kemudian memberikan solusi dan motivasi kepada dewan untuk meningkatkan kerjasama dengan semua pihak, terutama masyarakat setempat agar pendidikan Alkhairaat dapat diperhatikan oleh masyarakat". Selanjutnya HM Noor Sulaiman mengatakan bahwa:

Evaluasi kinerja guru dilakukan oleh Sayid Idrus dilakukan dengan sistem rotasi dan mutasi. Guru beberapa waktu mengajar di suatu tempat dan kemudian pindah ke daerah lain, terutama daerah yang baru dibuka pendidikan Alkhairaat. Selanjutnya Mereka digantikan oleh guru-guru lain, terutama guru baru yang lulus dari Alkhairaat, Sayid Idrus juga mengevaluasi kualitas guru dengan meningkatkan kualitas melalui memberikan bimbingan langsung atau dengan memberikan kesempatan bagi guru untuk membaca buku atau membaca buku untuk Sayid Idrus bin Salim Aljufrie ketika dikunjungi. ${ }^{26}$

Evaluasi prestasi belajar siswanya dilakukan oleh Sayid Idrus bin Salim Aljufrie dalam tiga bentuk yaitu; evaluasi dilakukan setiap triwulan, evaluasi dilakukan pada akhir tahun dan evaluasi ketika siswa kembali ke masyarakat, apakah itu bertindak sebagai pengkhotbah atau pendidik. Evaluasi ketiga dianggap sebagai evaluasi terberat karena hasil evaluasi diperoleh Sayid Idrus melalui penilaian publik. Jika seorang siswa yang dikirim ke komunitas untuk mengajar dan berkhotbah atau memimpin komunitas dan dianggap telah berhasil, maka ia telah berhasil dalam evaluasi. Walaupun model evaluasi ini unik dan membutuhkan proses yang panjang, tetapi untuk Sayid Idrus bin Salim Aljufrie bentuk evaluasi ini dianggap ideal karena merupakan sistem penilaian yang paling nyata dan obyektif. ${ }^{27}$

\section{KESIMPULAN}

Sayid Idrus bin Salim Aljufrie adalah salah satu cendekiawan dan pendidik hebat. Dia memiliki konsep manajerial yang kuat untuk mengembangkan pendidikan di Indonesia. Ini terbukti dari kemampuannya melakukan fungsi-fungsi manajerial seperti perencanaan, pengorganisasian, implementasi dan evaluasi / pengawasan.

Sayid Idrus membuat proses perencanaan pendidikan mulai dari perencanaan hingga membuka madrasah, infrastruktur yang akan digunakan hingga grand opening.

${ }^{25}$ Yanggo, Sayyid Idrus bin Salim Aljufri, Pendiri Alkhairaat dan Kontribusinya dalam Pembinaan Umat.........., h. 99.

${ }^{26} \mathrm{Ibid}$.

${ }^{27}$ Ibid. 
Proses mengorganisasikan pendidikan mulai dari pengorganisasian dalam perekrutan siswa baru, pembelajaran, hingga lembaga. Implementasi proses pendidikan dilakukan dengan menggabungkan dua sistem pendidikan khalaqah dan sistem klasik. Proses untuk mengevaluasi dan memantau pendidikan mereka dilakukan dalam tiga bentuk yaitu evaluasi dan pengawasan pelaksanaan pendidikan, evaluasi kinerja guru dan evaluasi hasil belajar siswa.

Dengan kemampuan manajemen pendidikan yang dimiliki, Sayid Idrus membuat pendidikan Alkhairaat tumbuh pesat di seluruh Indonesia bagian timur, dan telah memberikan kontribusi yang signifikan dalam pengembangan pendidikan Indonesia, khususnya dalam pengembangan sumber daya manusia yang berkualitas. Untuk layanan dan peran pentingnya dalam pengembangan pendidikan di Indonesia, pada 2011 Pemerintah Republik Indonesia memberikan Sayid Idrus bin Salim Aljufrie sebagai pahlawan nasional.

\section{DAFTAR PUSTAKA}

Fuaduddin, 2016. Pendidikan Ma'had Aly, Menyoal Tradisi Keilmuan Pesantren, Jurnal Edukasi; Jurnal Penelitian Pendidikan Agama dan Keagamaan.

Julitriarsa, D., 2012. dan Suprihanto J. Manajemen Umum Sebuah Pengantar, Yogyakarta BPFE.

Pidarta, M. 2008. Manajemen Pendidikan Indonesia, Jakarta : Bina Aksara.

Rahardjo. D, 2005. Bilik-Bilik Pesantren, Jakarta : LP3ES.

Rusmawan, 2016, Faktor Yang mempengaruhi Kesulitan Belajar IPS Siswa Sekolah Dasar Jurnal-Cakrawala Pendidikan, Jurnal Ilmiah Pendidikan.

Rudiyati.S. 2016. Peningkatan Kompetensi Guru Sekolah Inklusif dalam Penanganan Anak Berkebutuhan Khusus Melalui Pembelajaran Kolaboratif, JurnalCakrawala Pendidikan, Jurnal Ilmiah Pendidikan.

Sugiyono, 2017, Metode Penelitian Kuantitatif, Kualitatif dan R\&D, Bandung, Alfabeta. h. 246

Sulaiman, M.N., Biografi S. Idrus bin Salim Aldjufrie, Palu, 1988

Suryabrata, S., 2008. Proses Belajar Mengajar di Perguruan Tinggi, Yogyakarta : Andi Offset.

Steenbrink, K.A. 2013. Pesantren, Madrasah, Sekolah, Jakarta : LP3ES.

Yanggo, H.T., 2013. Sayyid Idrus bin Salim Aljufri, Pendiri Alkhairaat dan Kontribusinya dalam Pembinaan Umat, Jakarta : Gaung Persada

Yayat M. Herujito, 2001, Dasar-Dasar Manajemen, Grasindo, Jakarta. h. 3

Yunus, M., 1984. Sejarah Pendidikan Islam di Indonesia, Jakarta : Hidakarya Agung

Idrus bin Salim Al-Jufri, https://id.wikipedia.org/wiki/Idrus_bin_Salim_Al-Jufri 